\title{
Emergency centre handover from the perspective of prehospital emergency care providers in Johannesburg, South Africa
}

\author{
Andrew William Makkink and Christopher Owen Alexander Stein \\ Emergency Medical Care, University of Johannesburg - Doornfontein Campus, \\ Doornfontein, South Africa, and \\ Stevan Raynier Bruijns \\ Emergency Medicine, University of Cape Town, Cape Town, South Africa
}

\begin{abstract}
Purpose - The purpose of this paper is to describe handover in the emergency centre from the perspective of prehospital emergency care providers in Johannesburg, South Africa. Reference to emergency centre handover from the prehospital perspective will have particular relevance to all deliverers of emergency centre handover. Design/methodology/approach - A purposive, cross-sectional design addressed the study aim by using a purpose-designed, validated, paper-based questionnaire to collect data relating to prehospital emergency care personnel's perspectives on emergency centre handover.

Findings - There were 175 completed questionnaires collected from South African prehospital personnel within the Johannesburg area. The response rate was $175 / 290$ or $62 \%$. Training on handover was described as poor. There was a general appreciation of mnemonics and how well they ensured that all relevant information was handed over. However, this was countered by poor familiarity of common mnemonics. Perception of the accuracy of their own and observed prehospital handovers was generally positive. Handover length was generally perceived to be appropriate. The qualification of emergency centre personnel was perceived to impact on how handovers were received.

Research limitations/implications - The study was limited to one geographical area and did not include all potential participants in the study area. The self-reported data collection meant that there was a risk of self-report bias. These factors may have negatively affected the generalisability of the data.

Originality/value - This paper seeks to describe perceptions related to emergency centre handover from the perspective of prehospital emergency care personnel. In doing so, it is postulated that there is the potential to use these findings to improve certain aspects of emergency centre handover.
\end{abstract}

Keywords Emergency centre, Handover, Mnemonic, Prehospital

Paper type Research paper

\section{Introduction}

Emergency centre handover is one of the higher risk activities within the patient care journey and has a substantial association with adverse events (Sujan et al., 2015). Effective handover is essential to continuity of care and absence thereof has the potential to increase the incidence of adverse events. In the emergency centre, there are usually two parties involved in patient handover: the prehospital emergency care personnel - who deliver the handover -

(c) Andrew William Makkink, Christopher Owen Alexander Stein and Stevan Raynier Bruijns. Published by Emerald Publishing Limited. This article is published under the Creative Commons Attribution (CC BY 4.0) licence. Anyone may reproduce, distribute, translate and create derivative works of this article (for both commercial and non-commercial purposes), subject to full attribution to the original publication and authors. The full terms of this licence may be seen at http://creativecommons.org/licences/by/4.0/ legalcode

Declaration of Competing Interest: The authors have no competing interests to declare.

The authors would to acknowledge all participants who were involved in this research.

Funding: There were no sources of external funding for this research.

Received 13 July 2020 Revised 30 November 2020 10 January 2021

Accepted 16 February 2021 
IJES

10,3

316

and the emergency centre personnel - who receive the handover. Some of the important variables in the process have already been defined within this study setting (Makkink et al., 2019). There are also a number of variables related to handover that affect the effectiveness of information transfer. Mnemonics, handover accuracy, handover duration, content quantity and quality all contribute.

The use of mnemonics to facilitate better handover is one such contributing variable (Abraham et al., 2014; Budd et al., 2007; Eng et al., 2017; Jensen et al., 2013). Mnemonics have been linked to better information transfer, but have also been linked to a lack of improvement in information retention by emergency centre staff (Talbot and Bleetman, 2007). Despite the number of mnemonics in use, its function is unclear and the evidence relating to its usefulness remains inconclusive (Wood et al., 2015). The perception of handover accuracy is complex, as it can be measured from the perspective of both the person delivering the handover and the person receiving it (Fitzpatrick et al., 2018; Kerr et al., 2014). Sufficient and manageable are often terms used to describe the ideal length of handovers, but both lack context. The actual time required to deliver a handover was previously estimated in one study to be between one to three minutes, which does not add any context either (Fitzpatrick et al., 2018). Information included in a handover depend on the reasons for the patient's attendance, the staff member delivering the handover's experience, expectations, education and prior experience as well as the busyness of the emergency centre (Bost et al.,2012). The disparity in expectation is a potential contributor to information distortion (Cleland et al., 2009). Undeniably, the absence of a standardised, emergency centre-specific handover tool exacerbates this expectation disparity.

Handover requires bidirectional, interprofessional communication that includes active involvement from both the person delivering the handover and the person receiving the handover (Wohlauer et al., 2013). The efficacy of interprofessional communication may affect the perception of attentiveness on the part of the person receiving the handover (Di Delupis et al., 2014). There is a prevailing perception that handover reception is generally poor in the emergency centre (Di Delupis et al., 2014). This study aimed to describe handover in the emergency centre from the perspective of prehospital emergency care providers in Johannesburg, South Africa

\section{Methods}

A purposive, cross-sectional design addressed the study aim by using a purpose-designed, validated, paper-based questionnaire to collect data.

The purpose-designed questionnaire was designed and guided by literature identified in a search using PubMed ${ }^{\circledR}$ (MEDLINE) to identify literature related to the study aim. Search terms included "hand over", "handover", "hand-off" and "handoff". Variations of these terms that were relevant to the themes were also explored. Where relevant, abstracts were read and if deemed appropriate, the uJoogle search engine (C) Innovative Interfaces, Inc. Emeryville, $\mathrm{CA}$ ) was used to access relevant sources. Full-text sources that were available underwent additional scrutiny and were classified according to relevance. There was a paucity of literature identified pertaining to prehospital emergency care to emergency centre handover. Likert-type, forced binary and open-ended questions made up the questionnaire. Prehospital emergency care personnel register in qualification-specific registration categories with the Health Professions Council of South Africa (HPCSA). Prehospital emergency care personnel categories surveyed and their relevant registration categories were as follows: emergency care practitioner (ECP register), national diplomate and critical care assistant (ANT register), basic ambulance assistant (BAA register), emergency care technician (ECT register) and ambulance emergency assistant (ANA register).

Reliability and validity of the questionnaire were addressed using a pilot study (Kazi and Khalid, 2012). The questionnaire was piloted using ten completed questionnaires from two participants registered on the ANT and two participants registered on the ECP register, three 
BAA-registered participants and three ANA-registered participants. Each participant completed the questionnaire and then provided specific comments or suggestions for improvement where they felt that these were necessary. The pilot study participants did not provide any significant comments, there were no significant omissions and responses from the pilot study were included in the dataset.

Potential participants were approached where they worked and were requested to complete the questionnaire. This included the completion of informed consent documentation. Questionnaires were also left at the locations for completion by persons not present during the study introduction session. Two private and one state-funded emergency medical services that were operational within the Johannesburg metropolitan area served as the source for participants.

A convenience sampling strategy was used to distribute 290 questionnaires. Completed questionnaires were collected from 175 respondents, a $62 \%$ response rate. Stratified sampling was not practical given the significant differences in numbers of registered practitioners per HPCSA category (South African Government, 2017). Total sample size was calculated using the data presented in the National Emergency Care Education and Training (NECET) Policy. Using the NECET data of 1,427 registered and working prehospital emergency care personnel within the province in which the study was conducted an online sample size calculation tool (https://surveysystem.com/sscalc.htm\#two) was used to determine sample size. Using a confidence limit of $99 \%$ and a margin of error (confidence interval) of $10 \%$ the calculated sample size was determined to be 150 .

Responses were captured manually into a Microsoft Excel spreadsheet Version 16.0.4966 (Microsoft Corporation, Redmond, Washington, USA) per registration category for analysis. Qualification and registration demographics were described as were median and interquartile ranges for the various experience categories. Frequencies and percentages for each response were calculated. "No response" responses were excluded from the dataset and calculations.

Open-ended question responses were typed verbatim into a Word ${ }^{\circledR}$ (Microsoft Office, Microsoft Corporation, Redmond, WA) document. The completed document was imported into Atlas.ti (version 7.5.12, Atlas.ti Scientific Software Development GmbH, Berlin, Germany) for coding, analysis and interpretation. Coding, analysis and interpretation was augmented by using computer-assisted qualitative data analysis software (CAQDAS) to link data segments and codes and to assist in identification of dominant themes. Transcripts were read and reread to ensure that there was not an overreliance on the CAQDAS software to serve as the driver of code generation (Silver and Lewins, 2014). The result was that the informants' experiences were described in a language that was similar to their own language (Sandelowski, 2015).

The University of Cape Town's Faculty of Health Sciences Human Research Ethics Committee approved the study (HREC/REF: 624/2012).

\section{Results}

A total of 290 questionnaires were distributed and 175 completed questionnaires were collected from $16(9 \%)$ ANT, 20 (11\%) ECP, 75 (43\%) BAA, $15(9 \%)$ ECT and $49(28 \%)$ ANA participants. The response rate was $175 / 290$, or $62 \%$. All questionnaires collected were included in the data. Respondents' levels of experience are reported in Table 1. Some participants did not complete the levels of experience section of the questionnaire meaning that the total responses in Table 1 may not be the same as the total sample size.

Participant responses to the Likert-type restricted response questions are reported in Table 2. There were some participants who omitted to complete some of the questions in this section.

There were $89(51 \%)$ prehospital emergency care personnel participants who had not received formalised handover training $84(49 \%)$ who indicated that they had received formal
Prehospital handover in the emergency centre 
IJES

10,3

\section{8}

training on handover and two $(1 \%)$ who did not answer the question. Participants were asked to indicate their familiarity with commonly used handover mnemonics. The results of specific mnemonic familiarity are depicted in Table 3 and per registration category data is depicted in Table 4.

Participants were requested to motivate their response to Question 4 in Table 2 as to why they felt that qualification of emergency centre personnel affected the reception of handover. The emerging theme was that participants associated higher qualification with better attentiveness and ability to contextualise the patient. Participant quotes are depicted in Box 1.

\section{Discussion}

The results of this study demonstrated a generally positive perception of certain aspects of emergency centre handover by prehospital emergency care personnel within the study area. Familiarity related to commonly used handover mnemonics was poor and there was a perception that qualification of the receiver of handover had an effect on how well the handover was received. The low number of prehospital emergency care personnel who indicated that they had had formal training on handover is not dissimilar to other studies (Di Delupis et al., 2014; Horwitz et al., 2006; Sarcevic et al., 2009; Thakore and Morrison, 2001). There is evidence to suggest that many handover techniques are learned "on the job" (Bost et al., 2012). The implication of this is that existing poor handover techniques would simply be replicated. Formalised training on handover may address some of the issues identified in this study. Di Delupis, Pisanelli and Di Luccio et al. observed no difference in handover practice after a lecture and micro-simulation intervention, but there was marked improvement in handover communication after high-fidelity simulations and debriefings (Di Delupis et al., 2014). Simulation training in handover has also been shown to improve handover communication amongst healthcare providers and to improve real-life handovers (Gordon and Findley, 2011).

The poor familiarity of handover mnemonics has been demonstrated in other studies. The MIST mnemonic has been shown to enjoy familiarity with only $20 \%(n=2)$ of paramedics and $53 \%(n=9)$ of trauma team members in a relatively small Australian study (Evans et al., 2010). A similar mnemonic, ATMIST, was the preferred mnemonic in only $36 \%(n=67)$ of participants in a Scottish study with ASHICE $(19 \%, n=35)$ and SBAR $(17 \%, n=31)$ second and third most preferred (Fitzpatrick et al., 2018). The results of this study confirm the generally poor prehospital familiarity related to mnemonic use in handover. Despite DeMIST having been chosen as the preferred handover method by the Emergency Medicine Society of South Africa (EMSSA) (Wallis, 2008), familiarity related to this mnemonic remains poor. None of the current handover mnemonics seem to have had their origins in the emergency centre and have been adopted in various guises to try and fill the gap that exists in the emergency centre. The inconsistent use of mnemonics and lack of structured processes have

Table 1. Respondents' levels of experience

\begin{tabular}{lccrrc}
\hline HPCSA register & $\begin{array}{c}<\text { years } \\
n(\%)\end{array}$ & $\begin{array}{c}5-10 \text { years } \\
n(\%)\end{array}$ & $\begin{array}{c}10-15 \text { years } \\
n(\%)\end{array}$ & $\begin{array}{c}>15 \text { years } \\
n(\%)\end{array}$ & ${\text { Median }(\mathrm{IQR})^{\text {a }}}^{\text {(\%) }}$ \\
\hline BAA & $20(38)$ & $24(46)$ & $6(12)$ & $2(4)$ & $6(6)$ \\
ANA & $4(9)$ & $11(25)$ & $17(39)$ & $12(27)$ & $13(8)$ \\
ECT & $3(21)$ & $5(36)$ & $4(29)$ & $2(14)$ & $10(7.25)$ \\
ANT & $1(6)$ & $5(31)$ & $4(25)$ & $6(38)$ & $14.5(11.75)$ \\
ECP & $4(22)$ & $6(33)$ & $5(28)$ & $3(17)$ & $6.5(7)$ \\
Total $^{\text {b }}$ & $32(22)$ & $51(35)$ & $36(25)$ & $25(17)$ &
\end{tabular}

Note(s): ${ }^{\mathrm{a}} \mathrm{IQR}=$ Interquartile range, ${ }^{\mathrm{b}}$ Non-responses meant that total responses were not equal to total participants 


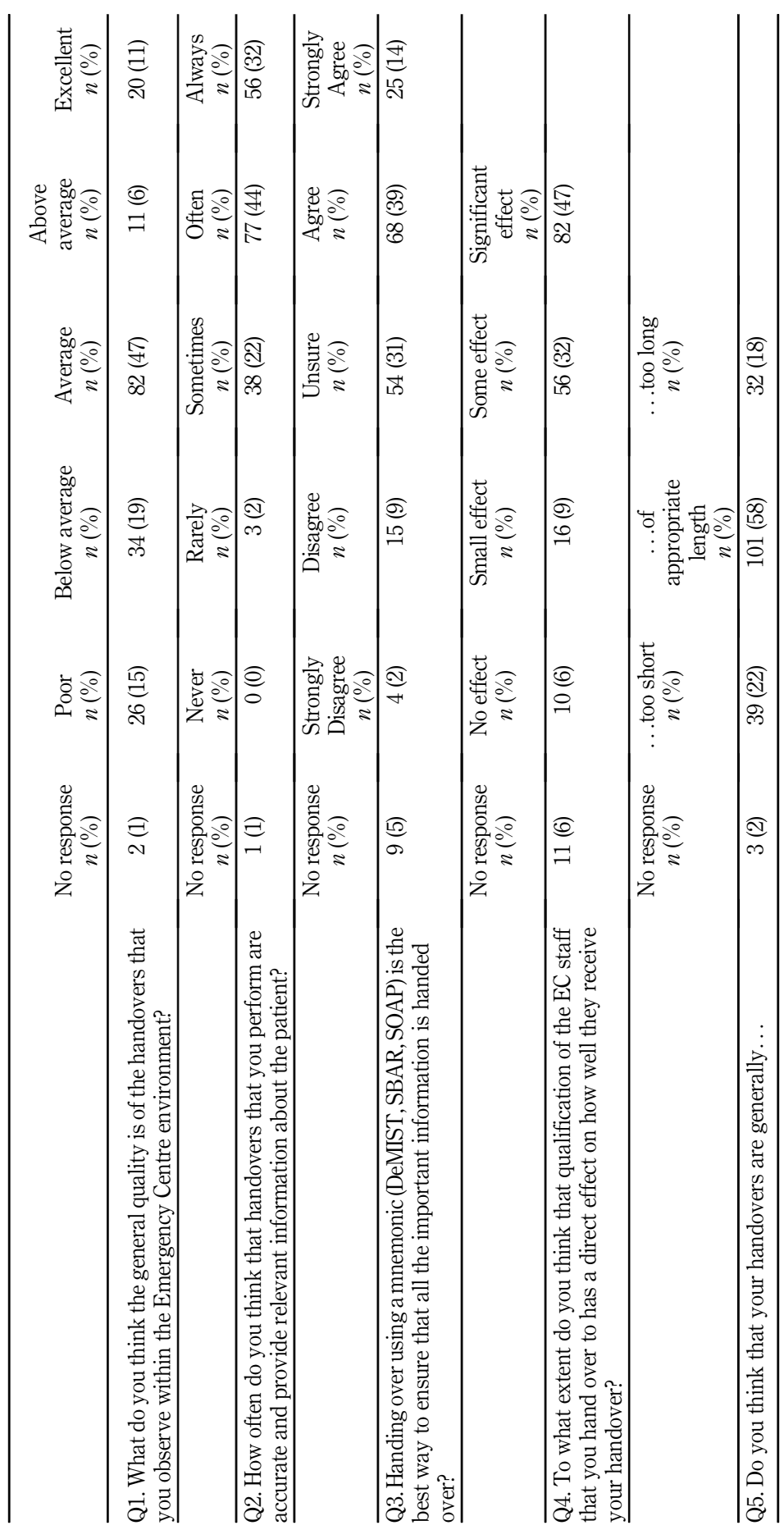

Prehospital handover in the emergency centre

319

Table 2.

Participant responses to Likert-type questions 
IJES

10,3

320

been identified as key issues in handover (Fitzpatrick et al., 2018). The fact that less than half of the participants in this study had been exposed to formalised handover training may be a reason why mnemonic familiarity was poor.

The development of an emergency centre-specific handover tool may assist in improving handover quality within the emergency centre. This can potentially be achieved by creating a malleable, semi-standardised structure where the order of presentation of data caters for the uniqueness of each patient presentation.

Concerns related to lack of attentiveness of emergency centre personnel to prehospital handover have been highlighted in a number of studies (Bost et al., 2012; Di Delupis et al., 2014; Thakore and Morrison, 2001). The perception of inattentiveness in the receiver has the potential to create a barrier to effective handover. Reason postulated for inattentiveness to prehospital handover has been the busyness of the emergency centre and the task-orientated nature of personnel (de Lange et al., 2018). A change towards better attentiveness has been referred to "learning to listen" (McMurray et al., 2010). The results of this study indicate that attentiveness is directly related to qualification (Table 3 and Box 1), but there were no other studies found that formed this link.

\section{Limitations}

The study was limited to one geographical area and did not include all emergency services, nor emergency departments in the study area. The self-report data collection meant that there was a risk of participant self-report bias and the distribution strategy may have affected response rates. These factors may have had a negative effect on the generalisability of the data. There were no corresponding emergency centre data gathered for comparative analysis. The hand-style collection of some questionnaires may have negatively affected the potential anonymity of those questionnaires. The use of a questionnaire to gather data may have meant that certain areas of emergency centre handover were not adequately explored meaning that there is scope for further study.

Future research should explore the lack of knowledge related to commonly used mnemonics amongst prehospital emergency care personnel. This despite their being aware of mnemonics and recognising their value. It would be valuable to expand the study to a wider geographical area. Further research based on qualification and scope may assist in better understanding prehospital handover delivery in the emergency centre. Given the potential resource disparities, it may be worthwhile to explore differing perspectives between private and state-funded EMS. It is also suggested that future research includes a larger sample and covers a wider geographical area. Similar work needs to be carried out to describe perceptions of handover from the perspective of emergency centre personnel.

Table 3.

Prehospital emergency care participant familiarity with commonly used handover mnemonics

\begin{tabular}{lcccr}
\hline Mnemonic & $\begin{array}{c}\text { No response } n \\
(\%)\end{array}$ & $\begin{array}{c}\text { Have never heard } \\
\text { of it } n(\%)\end{array}$ & $\begin{array}{c}\text { Unfamiliar, but have } \\
\text { heard of it } n(\%)\end{array}$ & $\begin{array}{c}\text { Familiar and use it myself } \\
\text { when I hand over } n(\%)\end{array}$ \\
\hline DeMIST $^{\mathrm{a}}$ & $21(12)$ & $83(47)$ & $34(19)$ & $37(21)$ \\
SOAP $^{\mathrm{b}}$ & $23(13)$ & $97(55)$ & $34(19)$ & $21(12)$ \\
SBAR $^{\mathrm{c}}$ & $24(14)$ & $117(67)$ & $26(15)$ & $8(5)$ \\
CUBAN $^{\mathrm{d}}$ & $24(14)$ & $124(71)$ & $23(13)$ & $4(2)$ \\
ASHICE $^{\mathrm{e}}$ & $25(14)$ & $129(74)$ & $15(9)$ & $6(3)$ \\
MIST $^{\mathrm{f}}$ & $12(7)$ & $49(28)$ & $33(19)$ & $81(46)$
\end{tabular}

Note(s): ${ }^{a}$ DeMIST - Patient Demographics, Mechanism of injury, Injuries sustained, Symptoms and signs and Treatment given; 'bSAP - Subjective, Objective, Assessment and Plan; 'SBAR - Situation, Background, Assessment and Recommendation; ${ }^{\mathrm{d} C U B A N}$ - Confidential, Uninterrupted, Brief, Accurate, Named personnel; eASHICE - Age, Sex, History, Injuries, Condition, Expected time of arrival; ${ }^{\mathrm{f}} \mathrm{MIST}$ - Mechanism of injury, Injuries sustained, Symptoms and signs and Treatment given 


\begin{tabular}{|c|c|c|c|c|c|}
\hline $\begin{array}{l}\text { Registration } \\
\text { category }\end{array}$ & Mnemonic & $\begin{array}{c}\text { No response } \\
n(\%)\end{array}$ & $\begin{array}{c}\text { Have never } \\
\text { heard of it } \\
n(\%)\end{array}$ & $\begin{array}{c}\text { Unfamiliar, but } \\
\text { have heard of it } \\
n(\%)\end{array}$ & $\begin{array}{c}\text { Familiar and use it } \\
\text { myself when I hand } \\
\text { over } n(\%)\end{array}$ \\
\hline \multirow[t]{6}{*}{ BAA } & DeMIST $^{\mathrm{a}}$ & $10(13)$ & 47 (63) & 11 (15) & 7 (9) \\
\hline & $\mathrm{SOAP}^{\mathrm{b}}$ & 11 (15) & $44(59)$ & 10 (13) & 10 (13) \\
\hline & SBAR $^{c}$ & 12 (16) & $50(67)$ & 10 (13) & $3(4)$ \\
\hline & CUBAN $^{\mathrm{d}}$ & 11 (15) & $51(68)$ & 11 (15) & $2(3)$ \\
\hline & ASHICE $^{\mathrm{e}}$ & 11 (15) & 55 (73) & $7(9)$ & $2(3)$ \\
\hline & MIST $^{f}$ & $7(9)$ & 31 (41) & $18(24)$ & 19 (25) \\
\hline \multirow[t]{6}{*}{ ANA } & DeMIST $^{\mathrm{a}}$ & 7 (14) & 26 (53) & $8(16)$ & $8(16)$ \\
\hline & $\mathrm{SOAP}^{\mathrm{b}}$ & 7 (14) & 31 (63) & 7 (14) & $4(8)$ \\
\hline & SBAR $^{c}$ & 7 (14) & 36 (73) & $3(6)$ & $3(6)$ \\
\hline & CUBAN $^{\mathrm{d}}$ & 7 (14) & 37 (76) & $3(6)$ & $2(4)$ \\
\hline & ASHICE $^{\mathrm{e}}$ & 7 (14) & 37 (76) & $2(4)$ & $3(6)$ \\
\hline & MIST $^{f}$ & $3(6)$ & $13(27)$ & 8 (16) & $25(51)$ \\
\hline \multirow[t]{6}{*}{ ECT } & DeMIST $^{\mathrm{a}}$ & 2 (13) & $4(27)$ & $1(7)$ & $8(53)$ \\
\hline & SOAP $^{\mathrm{b}}$ & 2 (13) & $6(40)$ & $3(20)$ & $4(27)$ \\
\hline & $\mathrm{SBAR}^{\mathrm{c}}$ & $1(7)$ & $8(53)$ & $5(33)$ & $1(7)$ \\
\hline & CUBAN $^{\mathrm{d}}$ & 2 (13) & $9(60)$ & $4(27)$ & $0(0)$ \\
\hline & ASHICE $^{\mathrm{e}}$ & $3(20)$ & $10(67)$ & $2(13)$ & $0(0)$ \\
\hline & MIST $^{f}$ & $1(7)$ & $3(20)$ & 2 (13) & $9(60)$ \\
\hline \multirow{6}{*}{ ANT } & DeMIST $^{\mathrm{a}}$ & 2 (13) & $2(13)$ & $5(31)$ & 7 (44) \\
\hline & $\mathrm{SOAP}^{\mathrm{b}}$ & 3 (19) & $4(25)$ & $8(50)$ & $1(6)$ \\
\hline & $\mathrm{SBAR}^{\mathrm{c}}$ & $4(25)$ & $8(50)$ & $4(25)$ & $0(0)$ \\
\hline & CUBAN $^{\mathrm{d}}$ & $4(25)$ & 11 (69) & $1(6)$ & $0(0)$ \\
\hline & ASHICE $^{\mathrm{e}}$ & $4(25)$ & $9(56)$ & 2 (13) & $1(6)$ \\
\hline & MIST $^{f}$ & $1(6)$ & $1(6)$ & $0(0)$ & $14(88)$ \\
\hline \multirow[t]{6}{*}{$\mathrm{ECP}$} & DeMIST $^{\mathrm{a}}$ & $0(0)$ & $4(20)$ & $9(45)$ & 7 (35) \\
\hline & SOAP $^{b}$ & $0(0)$ & $12(60)$ & $6(30)$ & $2(10)$ \\
\hline & $\mathrm{SBAR}^{\mathrm{c}}$ & $0(0)$ & 15 (75) & $4(20)$ & $1(5)$ \\
\hline & CUBAN $^{\mathrm{d}}$ & $0(0)$ & $16(80)$ & $4(20)$ & $0(0)$ \\
\hline & ASHICE $^{\mathrm{e}}$ & $0(0)$ & $18(90)$ & $2(10)$ & $0(0)$ \\
\hline & MIST $^{f}$ & $0(0)$ & $1(5)$ & $5(25)$ & $14(70)$ \\
\hline
\end{tabular}

Note(s): ${ }^{2}$ DeMIST - Patient Demographics, Mechanism of injury, Injuries sustained, Symptoms and signs and Treatment given; ' $\mathrm{B} O A P$ - Subjective, Objective, Assessment and Plan; 'SBAR - Situation, Background, Assessment and Recommendation; ${ }^{\mathrm{d} C U B A N}$ - Confidential, Uninterrupted, Brief, Accurate, Named personnel; ${ }^{\mathrm{e}}$ ASHICE - Age, Sex, History, Injuries, Condition, Expected time of arrival; ${ }^{\mathrm{f}} \mathrm{MIST}$ - Mechanism of injury, Injuries sustained, Symptoms and signs and Treatment given

Prehospital handover in the emergency centre 321

\section{Box. 1 Participant quotes related to their perceptions of the effect that emergency centre personnel qualification had on handover reception}

(1) "I have noticed that junior nursing staff are prone to disregarding handovers while senior nurses will take more time and pay more attention."

(2) "Lower qualifications tend to lose what I am saying, especially if it is a priority one patient. If they do not understand what I am saying they turn off"

(3) "In general the lower qualified the receiving health care worker is the less interested they are in a full handover"

(4) "The higher qualified the staff member the more they take on board the information that is being handed over and will interact with you."

(5) "Higher levels of trained staff are generally more attentive, know what to listen to and questions to ask"

(6) "EC staff with limited qualification tend to stop listening and lose interest in the handover when it exceeds their level of qualification." 
IJES

10,3

\section{Conclusion}

Perceptions related to emergency centre handover accuracy and length were generally positive but the poor levels of training and mnemonic familiarity were identified as cause for concern. The qualification of emergency centre personnel was perceived to impact on how handovers were received where lower qualification was linked to poorer handover reception. This research adds to the existing body of knowledge and provides important information related to emergency centre handover from the perspective of the prehospital emergency care provider. This information can be used to improve certain aspects of emergency centre handover.

\section{References}

Abraham, J., Kannampallil, T.G., Almoosa, K.F., Patel, B. and Patel, V.L. (2014), "Comparative evaluation of the content and structure of communication using two handoff tools: implications for patient safety", Journal of Critical Care, Vol. 29 No. 2, pp. 311.e1-311.e7.

Bost, N., Crilly, J., Patterson, E. and Chaboyer, W. (2012), "Clinical handover of patients arriving by ambulance to a hospital emergency department: a qualitative study", International Emergency Nursing, Vol. 20 No. 3, pp. 133-141.

Budd, H.R., Almond, L.M. and Porter, K. (2007), "A survey of trauma alert criteria and handover practice in England and Wales", Emergency Medicine Journal, Vol. 24 No. 4, pp. 302-304.

Cleland, J.A., Ross, S., Miller, S.C. and Patey, R. (2009), “There is a chain of Chinese whispers ...': empirical data support the call to formally teach handover to prequalification doctors", Quality and Safety in Health Care, Vol. 18 No. 4, pp. 267-271.

de Lange, S., van Eeden, I. and Heyns, T. (2018), "Patient handover in the emergency department: 'How' is as important as 'what", International Emergency Nursing, Elsevier, Vol. 36, pp. 46-50.

Di Delupis, F.D., Pisanelli, P., Di Luccio, G., Kennedy, M., Tellini, S., Nenci, N., Guerrini, E., Pini, R. and Gensini, G.F. (2014), "Communication during handover in the pre-hospital/hospital interface in Italy: from evaluation to implementation of multidisciplinary training through high-fidelity simulation", Internal and Emergency Medicine, Vol. 9 No. 5, pp. 575-582.

Eng, H.S., Teh, A., Kin, G., Mani, T.A.P., Kin, A.T.G. and Mani, T.A.P. (2017), "Effects of situation , background, assessment, and recommendation (SBAR) usage on communication skills among nurses in a private hospital in Kuala Lumpur", Journal of Krishna Institute of Medical Sciences University, Vol. 6 No. 2, pp. 74-79.

Evans, S.M., Murray, A., Patrick, I., Fitzgerald, M., Smith, S. and Cameron, P. (2010), "Clinical handover in the trauma setting: a qualitative study of paramedics and trauma team members", Quality and Safety in Health Care, Vol. 19 No. 6, e57, pp. 1-6.

Fitzpatrick, D., McKenna, M., Duncan, E.A.S., Laird, C., Lyon, R. and Corfield, A. (2018), "Critcomms: a national cross-sectional questionnaire based study to investigate prehospital handover practices between ambulance clinicians and specialist prehospital teams in Scotland", Scandinavian Journal of Trauma, Resuscitation and Emergency Medicine (SJTREM), Vol. 26 No. 1, pp. 1-11.

Gordon, M. and Findley, R. (201), "Educational interventions to improve handover in health care: a systematic review", Medical Education, Vol. 45 No. 11, pp. 1081-1089.

Horwitz, L.I., Krumholz, H.M., Green, M.L. and Huot, S.J. (2006), "Transfers of patient care between house staff on internal medicine wards", Archives of Internal Medicine, Vol. 166, pp. 1173-1177.

Jensen, S.M., Lippert, A. and Østergaard, D. (2013), "Handover of patients: a topical review of ambulance crew to emergency department handover", Acta Anaesthesiologica Scandinavica, Vol. 57 No. 8, pp. 964-970.

Kazi, A.M. and Khalid, W. (2012), "Questionnaire designing and validation”, Journal of Pakistan Medical Association, Vol. 62 No. 5, pp. 514-516. 
Kerr, D., Lu, S. and Mckinlay, L. (2014), "Towards patient-centred care: perspectives of nurses and midwives regarding shift-to-shift bedside handover", International Journal of Nursing Practice, Vol. 20 No. 3, pp. 250-257.

Makkink, A.W., Stein, C.O.A., Bruijns, S.R. and Gottschalk, S. (2019), "The variables perceived to be important during patient handover by South African prehospital care providers", African J Emerg Med, Vol. 9 No. 2, pp. 87-90.

McMurray, A., Chaboyer, W., Wallis, M. and Fetherston, C. (2010), "Implementing bedside handover: strategies for change management", Journal of Clinical Nursing, Vol. 19 Nos 17-18, pp. 2580-2589.

Sandelowski, M. (2015), "A matter of taste: evaluating the quality of qualitative research", Nursing Inquiry, Vol. 22 No. 2, pp. 86-94.

Sarcevic, A., Street, H. and Burd, R.S. (2009), "Information handover in time-critical work", Proceedings of the 2009 International ACM SIG Group Conference on Supporting Group Work, GROUP 2009, Sanibel Island, FL, May 10-13, 2009.

Silver, C. and Lewins, A.F. (2014), "Computer-assisted analysis of qualitative data”, in Leavy, P. (Ed.), The Oxford Handbook of Qualitative Research, Oxford University Press, New York, NY, pp. 606-638.

South African Government (2017), National Emergency Care Education and Training Policy, National Department of Health, Pretoria.

Sujan, M., Spurgeon, P. and Cooke, M. (2015), "The role of dynamic trade-offs in creating safety - a qualitative study of handover across care boundaries in emergency care", Reliability Engineering and System Safety, Vol. 141, pp. 54-62.

Talbot, R. and Bleetman, A. (2007), "Retention of information by emergency department staff at ambulance handover: do standardised approaches work?", Emergency Medicine Journal, Vol. 24 No. 8, pp. 539-542.

Thakore, S. and Morrison, W. (2001), "A survey of the perceived quality of patient handover by ambulance staff in the resuscitation room”, Emergency Medicine Journal, Vol. 18, pp. 293-296.

Wallis, L. (2008), "Practice guideline (EM007): patient handover at emergency centres", Emergency Medicine Society of South Africa, pp. 1-3.

Wohlauer, M., Arora, V., Horwitz, L., Bass, E., Mahar, S. and Philibert, I. (2013), "The patient handoff: a comprehensive curricular blueprint for resident education to improve continuity of care", Academic Medicine, Vol. 87 No. 4, pp. 411-418.

Wood, K., Crouch, R., Rowland, E. and Pope, C. (2015), “Clinical handovers between prehospital and hospital staff: literature review”, Emergency Medicine Journal, Vol. 32 No. 7, pp. 577-581.

\section{Corresponding author}

Andrew William Makkink can be contacted at: amakkink@uj.ac.za 


\section{Annexure 1: Questionnaire}

\section{4}

What do you think the general quality is of the handovers that you observe within the Emergency Centre environment?

\begin{tabular}{|l|l|l|l|l|}
\hline Poor & Below Average & Average & Above Average & Excellent \\
\hline
\end{tabular}

Handing over using a mnemonic (DeMIST, SBAR, SOAP) is the best way to ensure that all the important information is handed over?

\begin{tabular}{|l|l|l|l|l|}
\hline $\begin{array}{l}\text { Strongly } \\
\text { Disagree }\end{array}$ & Disagree & Unsure & Agree & Strongly Agree \\
\hline
\end{tabular}

How often do you think that handovers that you perform are accurate and provide relevant information about the patient?

\begin{tabular}{|l|l|l|l|l|}
\hline Never & Rarely & Sometimes & Often & Always \\
\hline
\end{tabular}

Do you think that your handovers are generally:

\begin{tabular}{|l|l|l|}
\hline Too short & Of appropriate length & Too long \\
\hline
\end{tabular}

Have you ever received formal training on how to hand over?

\begin{tabular}{|l|l|}
\hline No & Yes \\
\hline
\end{tabular}

Please indicate by making a cross which of the following handover mnemonics you are familiar with:

\begin{tabular}{|l|l|l|l|}
\hline & $\begin{array}{l}\text { Have never heard } \\
\text { of it }\end{array}$ & $\begin{array}{l}\text { Unfamiliar, but have } \\
\text { heard of it }\end{array}$ & $\begin{array}{l}\text { Familiar and use it } \\
\text { myself when I hand } \\
\text { over }\end{array}$ \\
\hline DeMIST & & & \\
\hline SOAP & & & \\
\hline SBAR & & & \\
\hline CUBAN & & & \\
\hline ASHICE & & & \\
\hline MIST & & & \\
\hline
\end{tabular}

To what extent do you think that qualification of the EC staff that you hand over to has a direct effect on how well they receive your handover?

\begin{tabular}{|l|l|l|l|}
\hline No effect & Small effect & Some effect & $\begin{array}{l}\text { Significant } \\
\text { effect }\end{array}$ \\
\hline
\end{tabular}

Please explain your answer:

List five things that you do that you believe make your handovers 'good'.

Please briefly discuss some aspects that can make the act of handing a patient over a 'bad' experience for you when you hand over in the Emergency Centre.

What do you think could be done to improve the standard of handover within the Emergency Centre?

I thank you for your time taken in completing this questionnaire and hope that this brings us closer to an improved handover process. 